\title{
Avaliar e gerir: força e miséria de um ideário presente nas políticas educacionais contemporâneas
}

WANDERSON FERREIRA ALVES

Universidade Federal de Goiás,

Goiânia, GO, Brasil

RESUMO

O objetivo deste artigo é indagar criticamente o projeto de mensuração do trabalho pedagógico presente em algumas das políticas educacionais contemporâneas, bem como o alcance da racionalidade gerencial que a acompanha, confrontando ambas à complexidade da atividade humana de trabalho. Trata-se de um texto de natureza teórica, elaborado com base em pesquisas no âmbito da educação e das ciências do trabalho. A primeira seção do artigo busca caracterizar as fontes e o alcance do "novo" management na educação. $\mathrm{Na}$ segunda seção, em uma direção inversa à precedente, a ideia é evidenciar limites e impasses da educação escolar orientada pela racionalidade gerencial. Na terceira seção, o propósito é discutir a dinâmica das situações de trabalho, a complexidade da atividade humana e os desafios que certos desenvolvimentos no mundo do trabalho atual impõem a toda tentativa de mensuração do trabalho. $\mathrm{O}$ texto finaliza com uma breve síntese das questões tratadas.

PALAVRAS-CHAVE

políticas educacionais; gestão da educação; avaliação educacional; trabalho; ergologia. 


\title{
ASSESSMENT AND MANAGEMENT: STRENGTH AND WEAKNESS OF A MINDSET IN CONTEMPORARY EDUCATIONAL POLICIES
}

\begin{abstract}
The aim of this paper is to investigate critically the project work relating to pedagogical measures present in some of the contemporary educational policies, as well as the scope of managerial rationality that accompanies it, which both confront the complexity of human labor. It is a text of a theoretical nature. It was developed from the crossing of two major areas: the study and research in education and research and studies in the sciences of labor. The first section of the text seeks to characterize the sources and highlight the scope of the "new" management education. In the second section the idea is to show the limits and impasses of education-oriented school managerial rationality. In the third section, the purpose is to discuss the dynamics of work situations, the complexity of human activity and the challenges that certain developments in the world of contemporary work pose for any attempt to impose a work measurement. The article concludes with a brief summary of the issues addressed.
\end{abstract}

\section{KEYWORDS}

educational policies; education management; educational assessment; work; ergology.

\section{EVALUAR Y ADMINISTRAR: FUERZA Y MISERIA DE UN IDEARIO PRESENTE EN LAS POLÍTICAS EDUCATIVAS CONTEMPORÁNEAS}

\section{RESUMEN}

El objetivo de este trabajo es investigar críticamente el proyecto de mensuración del trabajo pedagógico presente en algunas de las políticas educativas contemporáneas, así como el alcance de la racionalidad gerencial que las acompaña, confrontando ambas cuestiones a la complejidad de la actividad humana del trabajo. Se trata de un texto de naturaleza teórica, desarrollado a partir de la investigación en el ámbito de la educación y de la investigación en el ámbito de las ciencias del trabajo. La primera sección del artículo tiene por objeto caracterizar las fuentes y el alcance del "nuevo" management en la educación. En la segunda sección -en dirección inversa a la precedente-, la idea es mostrar los límites y obstáculos de la educación escolar orientada por la racionalidad administrativa. En la tercera sección, el propósito es analizar la dinámica de las situaciones de trabajo, la complejidad de la actividad humana y los desafíos que ciertos acontecimientos en el mundo del trabajo actual imponen a toda tentativa de mesnsuración del trabajo. El artículo concluye con una breve síntesis de los temas tratados.

\section{PALABRAS CLAVE}

políticas educacionales; gestión educacional; evaluación de la educación; trabajo; ergología. 
Deslizem mortais, não se apoiem, o gelo sob seus passos é frágil. (Pierre-Yves Narvor apud Supiot, 2007, p. 13) ${ }^{1}$

\section{INTRODUÇÃO}

Se as reformas educacionais ao fim do século $\mathrm{XX}$ trouxeram os professores para o centro do debate educacional com base em uma retórica que alardeava seu papel crucial no êxito da educação escolar, tal redirecionamento do olhar não restou sem consequências para os professores e seu trabalho. Edificadas no contexto da "modernidade gestionária" (Bruno, 2008) e por ela informada, as reformas aportaram na educação escolar determinado ideário e tecnologias (gestão para resultados, benchmarking etc.) reputadas como capazes de apreender o que ocorre nos sistemas de ensino e em cada uma de suas escolas.

Porém, como se pode depreender, nesse domínio não é suficiente conhecer: a racionalidade gestionária não apenas colhe informações, mas busca modelar aquilo sobre o qual incide. Tal racionalidade partilha do que Vatin (2008) denomina de espírito de engenheiro, o que corresponde a um modo de construção do conhecimento marcado pela preocupação com a medida, com a formalização e o cálculo, mas também voltado à ação. Não por outro motivo, autores de diferentes países notaram que mais do que propriamente orientada ao âmbito pedagógico, a avaliação transformou-se em instrumento de gestão. Evidentemente com nuances, a questão aparece em países tão distintos como o Brasil, os Estados Unidos, o Canadá e importante número de países europeus (cf. respectivamente, Sousa, 2005; Ravitch, 2011; Lessard, 2008; Mons, 2009). Mas o que explica a emergência desse gênero de fenômeno transnacional? Roger Dale (2004) apresenta uma argumentação que desperta interesse.

Em seus textos, Dale (idem) enfaticamente chama a atenção para o fato de que certas disposições no âmbito das políticas educacionais são bem mais que uma sorte de cultura comum entre países, sendo, em contraste, mais bem compreendidas no quadro do processo de globalização e de mudanças na esfera do estado, cujo móvel central, ele assinala, é o próprio sistema capitalista. A globalização - processo econômico, político e cultural - arrasta com ela características como "hiperliberalismo, governação sem governo e mercadorização e consumismo" (idem, p. 436). Assim, apreendendo a globalização com base nessa perspectiva e em seus desdobramentos para o campo educacional, Dale mostra como o provimento das escolas - isto é, a instituição dos meios para que estas cumpram suas finalidades institucionais - no mundo atual não é separável do debate sobre seu financiamento e formas de regulação.

Esse entendimento - detalhe importante - permite compreender, para além de contextos particulares, a direção de sentido que em diferentes países assume temas como o das formas de custeio, avaliação, gestão e controle da educação escolar,

1 Epígrafe de abertura de Homo juridicus: ensaio sobre a função antropológica do direito, de Alain Supiot (2007). 
aspectos que fazem laço direto com certo ideário político-econômico, com processos de desresponsabilização do Estado e com o papel dos organismos internacionais (Banco Mundial, Organização para Cooperação e Desenvolvimento Econômico OCDE, entre outros). E estas, como se sabe, são instâncias que, entre outras ações, engajam-se no fomento de um modelo de administração gerencial, o que ajuda a entender o epicentro da vulgata da autonomia, do accountability, situações de quase mercado educacional, obrigação de resultados etc.

O quadro delineado por Dale permite uma perspectiva de análise mais ampla da racionalidade gestionária no campo educacional, pois, ao passo que possibilita identificar e considerar as políticas e práticas de gestão, igualmente explicita o que as coloca em movimento - a agenda educacional inscrita nas tensões do sistema capitalista.

Gostaria de destacar esse aspecto mencionado, pois ele parece importante por mais de um título. Em primeiro lugar, porque permite escapar da pesquisa do tipo "catálogo", isso no sentido de que a análise não ultrapassa o apontamento meramente ilustrativo das políticas e ações da gestão no fio do tempo, como nas ocasiões em que, por exemplo, o pesquisador limitava-se a apontar que o pagamento por desempenho docente já existia nos Estados Unidos em 1920 ou que as práticas de avaliação padronizada remontam a este ou aquele período. Não basta indicar a existência da ferramenta de gestão, é preciso situá-la no tempo histórico e explicar como e por que ela ganha movimento. Em segundo lugar, porque, se considerarmos o ensino como trabalho, a questão trazida por Dale ganha um interessante valor heurístico: falaremos, então, em organização do trabalho pedagógico da escola, do trabalho no âmbito de um sistema de ensino, em trabalho dos professores.

Ora, em larga medida, a racionalidade gestionária não incide justamente sobre tudo isso? Reencontramos ao fundo a tensão entre capital e trabalho e, nesse domínio, a estreiteza das práticas de gestão diante da complexidade do trabalho humano. Por essa perspectiva de análise, as políticas e a gestão encontram-se em última instância com a atividade humana de trabalho, incidem sobre o trabalho realizado por homens e mulheres nas escolas. É essa tensão, instada por uma racionalidade que, como vimos nos parágrafos precedentes, busca mensurar e gerir o trabalho, que está no centro das reflexões aqui apresentadas.

Considerando o quadro delineado, evidentemente sem a pretensão de um exame exaustivo da questão nos limites de um artigo, o presente texto propõe-se a indagar criticamente o projeto de mensuração do trabalho pedagógico presente em algumas das políticas educacionais contemporâneas, bem como o alcance da racionalidade gerencial que a acompanha, confrontando ambas com a complexidade da atividade humana de trabalho. Trata-se de um texto de natureza teórica, que foi elaborado com base no cruzamento de duas grandes áreas: os estudos e pesquisas no âmbito da educação e os estudos e pesquisas no âmbito das ciências do trabalho (sociologia do trabalho, ergonomia da atividade etc.). Com base na demanda imposta pelo objeto - o ensino como trabalho -, e acreditando em um enriquecimento mútuo das áreas mencionadas, pensar a educação valendo-se do arsenal teórico-metodológico das disciplinas que têm o trabalho como objeto de estudo mostra-se pertinente e pode ser bastante profícuo. O leitor julgará. 
O texto está organizado em três seções. A primeira busca caracterizar as fontes e destacar o alcance do "novo" management na educação. A esse respeito argumentarei que, por diversas vias, a racionalidade gestionária recobre diferentes realidades e mostra sua força. Na segunda seção, em uma direção inversa a precedente, a ideia é evidenciar limites e impasses da educação escolar orientada pela racionalidade gerencial. Com base em alguns estudos e pesquisas, argumentarei que os "desvios" identificados não são aspectos a serem simplesmente "retificados", mas sim o próprio resultado de uma perspectiva que busca mensurar e gerir algo sobre a qual ela incide - em última instância, o trabalho humano - e que, em larga medida, permanece por ela ignorado ou reduzido a objeto. Na terceira seção, o propósito é discutir a dinâmica das situações de trabalho, a complexidade da atividade humana e os desafios que certos desenvolvimentos no mundo do trabalho contemporâneo impõem a toda tentativa de mensuração do trabalho. O texto finaliza com uma breve síntese das questões tratadas.

\section{A FORÇA DE UM IDEÁRIO}

Como aponta Claude Lessard (2008), um pouco em todo lugar e mais e mais no serviço público, a questão da obrigação de resultados impõe-se. Expressão que traz com ela um cortejo de elementos conexos:

Esta expressão carrega um cortejo de "conceitos" e ferramentas mais frequentemente utilizados no management que em educação: eficácia, eficiência, rendimento, produtividade, gestão da qualidade, busca de excelência, prestação de contas, imputabilidade, avaliação das instituições e de seus atores, plano de êxito, normas ISO, competição ou "cooperação", regulação pelo mercado, aproximação a necessidade do cliente, abordagem por competências, sistemas de prêmios por rendimento, indicadores, padrões. Há toda uma retórica gerencial aqui, como também uma linguagem de performance e de exigência de rendimento. (idem, p. 23, grifos do original)

A essa questão da obrigação de resultados é preciso ajuntar outras, a questão das mudanças na forma de financiamento, a descentralização, a formação de quase mercados etc. É que a racionalidade gestionária não se expressa em forma, mas em formas. Compreendê-la envolve encontrar a problemática da relação entre Estado e sociedade. A esse respeito, se falamos especialmente do serviço público, o assunto forçosamente encontrará o tema do New Public Management.

Como destaca Merrien (1999), na esteira da vaga neoliberal a partir dos anos de 1970, a administração pública foi questionada quanto à sua eficiência, e ações direcionadas à sua renovação foram postas em marcha em diferentes países. Nascida nos Estados Unidos, uma corrente da administração ganhará expressão internacional ao propor um sistema de racionalização das ações do Estado, prometendo melhor relação custo-eficácia e utilizando para isso modelos e ferramentas de gestão do setor privado. Trata-se do movimento conhecido por New Public Management, ou Nova Gestão Pública. 
Mons (2009) apresenta um resumo com alguns dos princípios desses novos modos de conceber a gestão pública. Estes partiriam dos seguintes pressupostos: a) a produção de serviços públicos é mensurável; b) sua mensurabilidade constitui-se graças a ferramentas específicas cuja validade deve ser cientificamente testada; c) os servidores públicos devem prestar contas de suas ações aos gestores e/ou aos cidadãos; d) a organização pública deve ser regulada por resultados, e não mais por meios procedimentais orientados com base na disponibilização de recursos.

Tais mudanças na administração pública não são desprezíveis. Nós sabemos. Nós as sentimos nas universidades à educação escolar. O alcance transnacional de tal racionalidade, enlaçando governos de direita e esquerda ávidos por reduzir as despesas públicas e reinventar o estado (Normand, 2005), é algo que impressiona. Nesse contexto, a situação dos professores e de seu trabalho não é decididamente confortável, pois, alçado a figura de destaque nas reformas, parte importante das "medidas modernizantes" apontadas anteriormente incidiu sobre eles. Nesse sentido bastante próprio, o trabalho docente foi "objeto" dessas políticas e ações de gestão. Sim, elas mostraram sua força. Vejamos o que disse uma professora de escola primária inglesa a Jeffrey e Woods (1998) em um livro cujo título diz muito, Testing teachers (Testando professores). No contexto das reformas neoliberais, ela dizia:

Meu trabalho atualmente não me satisfaz como antigamente, quando trabalhava com crianças pequenas, porque me sinto culpada cada vez que faço alguma coisa intuitiva. Isso está certo? Estou fazendo do jeito certo? Será que abrange o que esperavam que eu cobrisse? Será que deveria fazer mais alguma coisa? Deveria estruturar mais? Será que é oportuno? Será que deveria ter feito? Você começa a questionar tudo que faz - hoje em dia existe uma sensação de culpa no ato de ensinar. Não sei se isto está ligado especialmente ao Ofsted [Office for Standards in Education, o órgão responsável pela Inspeção das Escolas na Inglaterra], mas é claro que isto se multiplica devido ao fato de que o Ofsted vai aparecer, porque você fica apavorada com a ideia de não conseguir se justificar quando eles chegarem. (Jeffrey; Woods apud Ball, 2005, p. 550)

Quando lemos depoimentos como esse, é possível perceber que não é pouco o que as políticas e práticas gerenciais estão colocando em marcha na educação escolar, bem como é igualmente possível perceber o importante lugar que nelas ocupam o tema da avaliação. Depoimentos semelhantes - tratando da fragilização da profissão, da perda do sentido na realização do trabalho, medo, insegurança etc. - podem ser encontrados em estudos de pesquisadores de diferentes países, como os presentes no livro de Ravitch (2011) sobre o sistema público de ensino nos Estados Unidos, como aqueles do livro coordenado por Baunay et al. (2010), no qual os professores relatam as dificuldades de ensinar no contexto das reformas educacionais na França ou, ainda, como nas falas dos professores da pesquisa realizada por Fernandes (2010) sobre as reformas educacionais na rede pública de São Paulo, no Brasil.

Certamente as diferentes realidades nacionais são irredutíveis. Elas integram, no sentido forte do termo, a história de cada nação. Não se pode dissolver a parte na racionalidade do todo. Todavia, e é sobre isso que insisto aqui, há uma racionalidade 
do todo. É justamente ela que, em âmbito global, parece cobrar sua força nas reformas educacionais contemporâneas.

\section{POLÍTICAS EXITOSAS?}

No ano de 2009 foi publicado um estudo de grande envergadura sobre o tema da avaliação dos sistemas educacionais. Trata-se de uma síntese de estudos e pesquisas europeias e norte-americanas sobre o tema, no qual a autora, Nathalie Mons, indagava sobre o que de fato sabemos a respeito dos efeitos teóricos e reais das avaliações padronizadas, aquelas "que visam mensurar as aquisições cognitivas dos alunos a partir de provas cuja concepção, administração e correção são uniformizadas"(Mons, 2009, p. 100).

Para os que advogam pelo novo management na educação, os resultados aos quais chega Mons não são alentadores, nada parece endossar a certeza colegial que os neogestores nutrem pelo assunto. Em primeiro lugar, parece ser frágil a sustentação teórica que vincula os sistemas de avaliação padronizada à evolução das aquisições escolares dos alunos; em segundo lugar, se as reformas sustentaram uma forte retórica em torno da questão, o conjunto das pesquisas mostra evidências empíricas bastante contraditórias quanto aos seus resultados; em terceiro lugar, o modelo de responsabilização que integra o testing parece ter implicações sobre esses resultados variáveis encontrados pelas pesquisas. Gostaria de destacar esse último ponto, a questão dos modelos de accountability ${ }^{2}$ e suas possíveis implicações. Veremos a seguir que por meio desse aspecto encontraremos alguns dos efeitos deletérios que tais políticas e práticas podem ter sobre o trabalho dos professores.

O que Mons denominou de "modelos de accountability" efetiva-se por vezes em formas muito diferentes, de acordo com as realidades nacionais e locais. Estas podem assumir feições diversas, mas há duas grandes tendências em âmbito internacional: perspectivas mais abertas ou mais fechadas, a primeira a autora nomeia como modelos de accountability douce (associado ao modelo continental europeu), e a segunda como modelos de accountability dure (associado ao modelo anglo-saxão). Estes últimos, sobretudo, têm implicações particularmente importantes para os professores, pois se trata de uma política centrada fortemente na prescrição do currículo, no controle, na incitação, na responsabilização e punição dos atores escolares.

Para os que propugnavam tais medidas (governos, consultores etc.), a máquina escolar assim azeitada só poderia funcionar bem, afinal as escolas estavam reproduzindo as formas que eles consideravam exitosas no setor privado. Todavia, as pesquisas não somente não confirmaram a positividade de tais políticas, como, do ponto de vista do exercício profissional docente, trouxeram dados preocupantes. O que a síntese das pesquisas apresentadas por Mons (idem) apresenta a esse respeito?

2 A expressão accountability é geralmente traduzida por "responsabilização"; todavia, trata-se de uma tradução precária, pois outros sentidos inerentes ao accountability não são contemplados. A referida expressão - e é essa a dificuldade da tradução - comporta três elementos articulados: a ideia de avaliação, de prestação de contas e de responsabilização. A esse respeito, ver Afonso (2009). 
As mencionadas pesquisas apontaram que certos dispositivos institucionais podem levar ao fenômeno conhecido como teaching to the test, ou seja, o treinamento intensivo para os testes: os professores passam a dedicar muito tempo do processo de ensino ao treinamento dos exercícios próximos àqueles que serão realizados nos testes, algo que foi bem estudado no caso inglês e norte-americano. As pesquisas identificaram que os dispositivos de avaliação padronizada podem levar ao estreitamento do currículo: como os testes concentram-se sobre um número limitado de disciplinas, os professores - sobretudo na escolarização inicial - tendem a dedicar menos tempo às disciplinas que não são avaliadas, assim, disciplinas como ciências sociais, educação artística e educação física tinham a carga horária diminuída.

As pesquisas mostraram que as avaliações padronizadas podem promover a contração do papel formativo da escola: os professores podem passar a focalizar sua ação sobre objetivos estritamente cognitivos, em detrimento de outras missões da escola, como a socialização, a autonomia, o desenvolvimento da criatividade etc. As avaliações padronizadas podem conduzir mudanças nas próprias práticas pedagógicas: cobrindo um amplo aspecto de conhecimentos que devem ser assimilados em um tempo limitado, as avaliações padronizadas podem levar os professores a buscar métodos pedagógicos pautados na memorização. As avaliações padronizadas, especialmente quando em contextos de forte pressão sobre os atores escolares, podem ter consequências importantes para a percepção que os professores têm dos alunos e a atenção que lhes será dada: fatos empiricamente constatados em Chicago e no Texas, os professores podem ser levados a categorizar os alunos (os brilhantes, os que podem ter êxito no teste com algum apoio e os que estão em fracasso durável), isolando aqueles que apresentam maiores dificuldades.

As avaliações podem conduzir à seletividade do público atendido pelas escolas: os estabelecimentos de ensino, inscritos em uma lógica concorrencial e no qual os resultados das avaliações são midiatizados, podem passar a ser mais seletivos em relação ao público que atende, recrutando os alunos que possam lhe oferecer a imagem de um estabelecimento destacado, bem classificado nas avaliações, mas também socialmente distinto em seu público; assim, recrutam-se os "bons alunos". Enfim, as avaliações padronizadas orientadas por dispositivos de accountability mais rígidos podem levar a tentativas de burlar o sistema para aumentar resultados: certas equipes pedagógicas podem tentar fraudar as avaliações com base na identificação prévia e consequente exclusão, no momento do teste, dos alunos que tenham menor rendimento, elevando assim a nota média global do estabelecimento, portanto, uma nota superior à realidade.

Questões como essas apontadas por Nathalie Mons em 2009 continuaram a ser relatadas pela literatura (Freitas, 2012; Guisbond; Neill; Schaeffer, 2012; Ravitch, 2011). Todavia, os defensores do novo management não se abalam. Eles entendem, e esse é o caso de Meuret (2007), que questões como as anteriormente descritas podem ser de fato um problema, mas que serão equacionadas à medida que os estudos evoluam e as ferramentas de gestão afinem-se - é a aventura de "governar as escolas”, como sublinha o título da própria obra de Meuret. Minha posição é, decididamente, muito menos otimista.

A esse respeito, entendo que o relatado nos parágrafos precedentes - tendência à ineficácia das políticas e gestão com efeitos deletérios sobre o que ela propõe a 
gerir - não é uma sorte de "desvio" e, portanto, matéria a ser "retificada" pela melhor calibragem dos processos gerenciais, mas a própria expressão da racionalidade gestionária ao se defrontar com o trabalho humano. Isso porque, por um lado, parece haver elementos intrínsecos a essa racionalidade que dilapidam seu próprio fazer, por outro, o trabalho humano apresenta uma complexidade irredutível. São esses aspectos que desenvolvo na seção seguinte.

\section{DAS POLÍTICAS EDUCACIONAIS AOS ENIGMAS DO TRABALHO}

Um fato "natural" intervém: uma explosão devido ao contato de diferentes materiais químicos em um determinado contexto [O autor faz referência a um grave acidente que resultou na explosão ocorrida na usina AZF, na

França, no ano de 2001]. Qual é o conjunto dos fatos de trabalho que, combinados, estão na origem deste acontecimento? Não poderíamos limitar a investigação a manipulaçôes locais, facilmente identificáveis: um operário que com a ajuda de uma pá teria jogado tal produto sobre outro. No inicio de tais gestos técnicos significativos da referência de nossas representaçôes antigas ainda vivas se situam quantidades de outros atos de trabalho, aparentemente abstratos, sem ligação direta com a natureza das coisas, inscritas sobre o papel ou em suportes eletrônicos e que, no entanto, participam do fato. Esse encadeamento complexo na origem de um evento destruidor, que a justiça tem a incumbência de examinar para imputar responsabilidades civis e penais, é por sua natureza equivalente àquela que acontece cotidianamente para gerar múltiplos eventos criadores cuja soma constitui a "produção".

VATin, 2008, p. 182

Como argumentei mais detidamente no início do presente texto, as políticas educacionais contemporâneas e as práticas de gestão que as acompanham defrontam-se, em última instância, com o trabalho humano. Em sua aparente banalidade, tal "encontro" porta mais dificuldades do que preveem as filosofias do management, como testemunha - em seu alcance e seus impasses - a história das formas sociais de organização e gestão do trabalho ao longo do último século. ${ }^{3}$ A esse respeito, uma qualificada literatura acadêmica - cujo marco talvez seja a obra seminal de Georges Friedmann, Problèmes humains du machinisme industriel, publicada em 1946 - não cansou de evidenciar a força e a abrangência, mas também os limites e as ilusões presentes em muitas dessas proposições interessadas em governar o trabalho.

Não há linha reta na relação entre gestão e trabalho, muito menos em sua questão de fundo quando se trata de nosso modelo societal: a contradição entre

3 Por exemplo, as ambições do taylorismo no tocante à estandardização máxima do momento produtivo; as pesquisas de Elton Mayo em Hawtorne e o "sentimento" do trabalhador como matéria a ser gerida; as tentativas de enriquecimento dos conteúdos do trabalho no âmbito do Tavistock Institute for Human Relations; a organização flexível da produção e as miragens do automatismo. Em uma literatura bastante vasta, uma excelente síntese sobre o conjunto de tais questões pode ser vista em Stroobants (2007). 
capital e trabalho. Na composição entre o que foi e o que será, o trabalho vivo resta portador de algo enigmático e a indagar os que desejam compreender os homens e as mulheres no trabalho. Como assinala François Vatin na epígrafe que abre esta seção, na mediação de inúmeros gestos criadores encadeados dentro e fora da situação de trabalho, a "produção" é uma incógnita.

Como explicar que se fala hoje em um trabalho fisicamente menos penoso, que em muitas áreas ampliam-se os sistemas automáticos, eletroeletrônicos, computacionais, mas que em contrapartida os casos de Lesões por Esforço Repetitivo (LER) e Distúrbio Osteomuscular Relacionado ao Trabalho (DORT) multiplicam-se e desembocam em um quadro paradoxal: de um lado, as pesquisas sobre a temática avançam mais e mais, de outro, o crescimento exponencial de novos casos prossegue (Coutarel; Daniellou; Dugué, 2005).

Ora, o que se apresenta nesses meios laborais? O que nele nos escapa? Como intervir de maneira pertinente? Outro exemplo, como entender o que se passa quando em um ambiente aparentemente agradável - limpo, bem iluminado, com estabilidade funcional e remuneração compatível etc. - a experiência laboral pareça por vezes dura demais, derivando inclusive em quadros patológicos no tocante à saúde mental do trabalhador (Codo, 2004). Como entender o que aí acontece? Trabalhar é simplesmente executar algo em troca do salário, como sugere o pensamento econômico mais restrito? Se fosse somente isso, as pessoas adoeceriam tal qual no caso relatado? O que ocorre nesse domínio que favorece ou não a saúde do trabalhador?

Como explicar o saber em trabalho de uma professora de química que, transitando entre as carteiras da sala de aula, realiza a gestão da classe e conduz o ensino dos conteúdos ritmando-o com base nos olhos dos alunos, captando neles o endosso para prosseguir ou não com matéria, ao passo que distingue no coletivo aqueles com mais facilidade no aprendizado daqueles que têm mais dificuldade e que, por isso, requerem maior atenção (Alves, 2010). Pode-se perguntar de modo direto: Quais elementos constituem o gesto de um profissional? O que engendra o gesto profissional competente? O que o interdita? O que o degrada? Que lugar ocupa a formação profissional nesse domínio? A relação entre indivíduo e coletivo de trabalho ajuda a compreender o que se passa ou, invertendo a questão à maneira de Clot (2003), deveríamos perguntar em que medida o coletivo está no indivíduo?

Seria possível ajuntar a essas interrogações outras, transitando assim pelo tema das dimensões coletivas do trabalho, do paradoxo das tecnologias, da eficácia, da produtividade, entre tantos outros. Todavia, nos limites deste texto, não seria o caso de prosseguir. Acredito que tenha sido possível ao leitor aquilatar que, quando se trata do trabalho humano, temos ainda um continente para conhecer ou, talvez, reconhecer. No entanto, o que se passa no mundo do trabalho atual? Portador de uma inextricável complexidade, no contexto em que as práticas gestionárias estendem-se sobre os mais variados campos - e mais e mais sobre o serviço público -, o trabalho parece se revestir de uma crescente opacidade.

A seguir, destacarei brevemente três aspectos que colaboram para isso: a visibilidade do trabalho prescrito e a invisibilidade do trabalho real; o desenvolvimento do setor terciário e os desafios que este coloca às práticas de gestão e avaliação do trabalho; a constituição de um contraditório mercado de firmas de consultoria. 


\section{DIMENSÕES VISÍVEIS E INVISÍVEIS NO TRABALHO}

Em uma empresa privada ou em uma instituição pública, quando se pergunta à direção desses estabelecimentos o que realizam, a primeira informação que oferecem é sobre o que produzem, com relação a bens ou serviço: fabricamos portões, somos especializados na construção de rodovias, prestamos assistência a idosos etc. Se continuarmos dialogando, esses interlocutores falarão sobre os meios que utilizam para obter o que foi apontado anteriormente e aquilo que pretendem adquirir para fazê-lo: falarão sobre quantidades a serem produzidas, prazos a cumprir, a qualidade dos produtos, dos meios materiais e financeiros, o número de estabelecimentos, as filiais, o faturamento, a capacidade de armazenamento, a tecnologia de produção etc. A organização do trabalho e os assalariados ali presentes são evocados tão somente em seu potencial de ação a serviço dos resultados esperados.

De maneira análoga, os trabalhadores falam de seu trabalho em termos da ação realizada ou "em termos de resultados a obter: 'ele embala produtos, ela costura vestidos, ela atende desempregados, ele dirige trens, ela administra apólices de seguro' etc.” (Guérin et al., 2001, p. 13). Eles apontam o que utilizam para tal, descrevendo "os meios que usam: 'eu disponho de um estoque de caixas de papelão, bandejas plásticas e uso um rolo de filme PVC, tenho uma máquina de costura, tenho um fichário e uso telefone', etc." (idem, ibidem). Empregadores e assalariados referem-se às tarefas que cumprem. Em larga medida, são aspectos como esses que são colhidos pelos canais especializados - relatórios de incidentes, balanços de custos, indicadores de desempenho dos assalariados etc. - que buscam avaliar o que se passa nas empresas privadas e nas instituições públicas.

O que acaba de ser descrito é a dimensão mais visível do trabalho. Ela compreende o que os ergonomistas chamam de trabalho prescrito. A noção de trabalho prescrito envolve um conjunto de elementos situados ex-ante as situações de trabalho: a perspectiva sobre o que será obtido, as condições determinadas de realização e, por fim, a tarefa, ou seja, o que deve ser realizado. Contudo, nas situações de trabalho, no trabalho real, vai-se do objetivo à realidade: há variações do contexto, as condições determinadas não são as condições reais, e o resultado visado não é totalmente o efetivado. Enfim, há diferença entre "o que se pede" e "o que a coisa pede" (idem, p. 15). Décadas de investigação empírica permitem que a ergonomia sustente sua distinção fundadora: a decalagem entre trabalho prescrito e trabalho real. A atividade dos homens e mulheres no trabalho situa-se no centro dessa problemática, pois é por ela que se compreende a maneira como os processos foram realizados, os meios que foram utilizados para se obter os resultados, as exigências que aquilo demandou, os incidentes que precisaram ser geridos, a saúde que se arriscou... Mas tudo isso não se vê.

O trabalho real, os compromissos que o operador faz para agir, não se vê... O real do trabalho (Dejours, 1995), com o qual o operador se confronta, como ele responde, o que ele mobiliza para se sair bem, o que ele arrisca, não se vê... Para nós, isto é uma opção essencial da ergonomia: é verdade que o comportamento comunica a parte manifesta do trabalho - visualmente, mas também verbalmente (as opiniões são comportamentos verbais); intencionalmente (o comportamento 
participa de uma estratégia de comunicação dos operadores), mas também não intencionalmente (o trabalho testemunha em parte de si próprio por si próprio). Mas ele não esgota a realidade que, por sua natureza, escapa ao olhar e justifica, sob a cobertura da análise da atividade, uma explicação que não se confunde com a observação nem com a análise dos comportamentos (behaviorismo).(Hubault, 2004, p. 107, grifos do original)

Se aquilo que é prescrito compreende a dimensão mais visível do trabalho, este não se reduz àquele. $\mathrm{Na}$ batalha do trabalho real, para usar uma expressão do ergonomista Alain Wisner, os trabalhadores dão prova de outra realidade para além das dimensões visíveis do trabalho. É fundamentalmente graças à sua atividade que a produção sai. ${ }^{4}$ Nesse aspecto - destaque importante -, as modernas práticas de gestão nas empresas privadas e os modelos gerenciais na administração pública contemporânea contribuem amplamente para o obscurecimento dessas dimensões não visíveis do trabalho. Sistemas de avaliação da performance dos assalariados e gestão por resultados são o corolário de um processo no qual aquilo que é do âmbito da atividade é mais e mais encoberto, o que não se faz sem derivar em contradições graves, inclusive para a saúde dos trabalhadores. ${ }^{5}$ Se o trabalho real resta revestido de uma crescente opacidade, certos desenvolvimentos socioeconômicos nas últimas décadas a alimentam ainda mais, trata-se da expansão do setor terciário.

\section{AVALIAR E GERIR, MAS O QUÊ?}

O setor terciário - ou, se se quiser, o setor de serviços - compreende um vasto conjunto formado por elementos muito diversos, como o comércio varejista, postos de combustível, serviços de telefonia, transporte público urbano, empresas aéreas, hospitais, entre outros elementos em inumeráveis ramos e campos de atuação. ${ }^{6}$ A questão em tela aqui é a da avaliação da eficácia e da eficiência no terciário. Questão importante, pois, como aponta Orban (2005), se a determinação do input e do output é problemática no mundo industrial, nos serviços ela se torna quase insolúvel. As reflexões apresentadas por Vidal, Muniz e Alvarez (2001) permitem uma boa aproximação da questão. Vejamos o que dizem esses autores.

Com base em uma pesquisa empírica sobre o trabalho em um hospital público no Rio de Janeiro e perguntando-se pela relação trabalho-gestão diante das características do setor terciário, Vidal, Muniz e Alvarez (idem) nos trazem questões que

4 Como vimos, a atividade humana de trabalho é o que possibilita que nas situações laborais o que precisa ser realizado seja realizado. Ela enlaça o corpo, a memória, a história partilhada da profissão, a subjetividade, as sinergias entre o coletivo, os usos de si do trabalhador (Schwartz; Durrive, 2007).

5 A esse respeito, ver os inúmeros casos relatados por Clot (2010).

6 Em sua heterogeneidade, ele é permeável a diversos tipos de arranjos institucionais, a modelos organizacionais e ocupacionais igualmente muito distintos. "Assim, ao mesmo tempo em que os serviços exprimem a modernidade dos tempos cibernéticos, também espelham as atividades tradicionais e precárias. O setor de serviços é tanto a lança do avanço tecnológico como a do atraso" (Melo; Marques, 2005, p. 177). 
merecem consideração. Em um primeiro instante, os autores delineiam um quadro da situação assinalando as dificuldades estruturais do hospital, como os problemas relativos ao financiamento e às condições de trabalho, e observam algumas das injunções do setor da saúde em torno das demandas da racionalidade gestionária: "a avaliação da performance através de resultados mensuráveis também está presente no contexto dos hospitais públicos", sublinham os autores. Nesse horizonte busca-se "avaliar a eficácia e a eficiência com base em indicadores quantitativos, como taxa de infecção, taxa de rotatividade de leitos e média de permanência hospitalar" (idem, p. 86).

É nesse quadro que os autores destacam como o trabalho no terciário escapa aos parâmetros do paradigma industrialista ao ser mais lábil, multiforme, mais difícil de ser padronizado e que, muitas vezes, por força da relação interativa aí presente é coproduzido na relação entre prestador e usuário. Determinar a eficácia, nesse âmbito, torna-se uma difícil questão: se por um lado é possível, por vezes, estabelecer indicadores quantitativos (diminuição do tempo médio de hospitalização, taxas de aprovação escolar etc.), por outro esse optimum previsto é permeado "de pressuposições, de reduções, por vezes de mutilações, quanto às condições reais de sucesso financeiro, mas também quanto às condições de sucesso social, da entidade econômica considerada" (idem,p. 81). Ora, com qual "metro" mensura-se o trabalho no terciário?

[Quando] se tenta dar um indicador de performance aos insumos, quando se tenta definir um numerador e um denominador no que tange ao setor de serviços. $\mathrm{Na}$ maioria dos casos busca-se definir um output. onde está o equivalente do produto a ser colocado no numerador? Como circunscrever um ato tendo começo e fim, regularidade reprodutiva, de tal maneira que se possa dizer: o mesmo ato foi produzido com menos (ou mais) insumos? Onde começa e onde termina a atividade de ensino, de recepção e informação pertinente a um usuário, o ato de cuidar, o tratamento de um dossiê médico, a manutenção de um equipamento, o conselho para uma aplicação financeira? A definição de inputs (denominador) é também problemática: existe a possibilidade de quantificar os meios, permitindo que se possa dizer que eles foram utilizados de maneira estável para produzir mais ou menos outputs? Seria necessário dispor de "referenciais constantes", análogos ao estoque de material, de máquinas, de horas de trabalho, supostos constantes e determináveis para produção de uma certa quantidade de bens. Quais são os materiais, as pessoas, as entidades institucionais pertinentes para dar conta da melhoria de um tratamento médico-hospitalar? [...]. A definição temporal também se torna frágil: qual é a unidade temporal pela qual podemos medir um serviço exterior de manutenção em relação a sua prestação? No caso dos serviços há um continuum temporal difícil de ser quantificado. $\mathrm{O}$ efeito de um serviço não se conclui em uma prestação temporal segmentada: o efeito de um serviço em termos cronológicos não é necessariamente assinalável e emerge no campo de valores sociais que concorrem, ou estão em conflito, fazendo inevitável retorno sobre os procedimentos de conceitualização econômica. (idem, ibidem) 
Nesse sentido, as características do trabalho no terciário questionam pela base os modos de proceder da gestão e sua noção de produtividade tributária do paradigma industrialista. Aqui, novamente, uma visão estreita do que é a gestão e do que é trabalhar produzem medidas facilmente deletérias para a qualidade do que uma instituição ou organização propõe-se a realizar, o que pode ser visto no caso do trabalho do médico-cirurgião relatado por Clot (2010), ou no caso do magistério na rede estadual paulista relatado por Alves (2012).

Em ambos os casos, as medidas gerenciais tentam governar o trabalho a partir de fora e desconsideram o trabalho real. De maneira mais direta no setor terciário, é preciso submeter tais métodos de avaliação e gestão à crítica se não se quiser continuar a perpetuar equívocos, suprimir postos de trabalho e oferecer menos na crença de que se oferece mais (Gadrey, 2001). Essa questão diz respeito à própria dimensão qualitativa do trabalho, mas é ela mesma que está em risco quando as práticas de gestão desconectam-se dos conteúdos que constituem o que se propõe gerir, fenômeno para o qual concorre a formação de um mercado de firmas de consultoria.

\section{UM MERCADO DE EXPERTS}

A modernidade gestionária, para usar a expressão de Bruno (2008), trouxe para as empresas um cortejo de ferramentas de gestão (downsizing, reengenharia de processo, lean production, planejamento estratégico, balanced scorecard, gestão da qualidade total, benchmarking etc.) e um corpo de profissionais que as coloca em movimento, em linhas gerais os consultores e os gestores profissionais, isto é, pessoas integralmente dedicadas a tal tarefa.

Arbitrando sobre assuntos internos e externos às empresas, difundindo conceitos a respeito do mundo empresarial e realizando mudanças organizacionais, as firmas de consultoria expandiram-se fortemente nos anos de 1980 e 1990, entre outros aspectos, alimentadas naquele contexto pelas tentativas de tradução das práticas japonesas (Donadone; Sznelwar, 2004). Tudo isso não ficou sem repercussão para a administração pública. Se a empresa privada constitui sua finalidade no acúmulo do capital, para a administração pública - o contexto é o do neoliberalismo e de correntes teóricas como o New Public Management - estava em jogo a redefinição de suas ações, a busca por modelos mais "leves" (o modelo burocrático será objeto de severas críticas) e eficientes, um terreno fértil para ferramentas de gestão prometendo planejamento estratégico, controle das ações, monitoramento do desempenho etc. Não é esse o terreno dos consultores? No Brasil, hoje, sem alarde, os consultores estão presentes na administração pública de vários estados da federação, desejosos de "modernizar" sua gestão, inclusive na pasta da educação.

7 A título de ilustração: o jornal Folha de S. Paulo, edição de 7 de maio de 2011, anunciou que o governo do estado de São Paulo firmou contrato com uma empresa de consultoria norte-americana, a McKinsey, tendo em vista melhorar o ensino de suas escolas. Segundo o jornal, a meta é que São Paulo entre na lista dos vinte e cinco melhores sistemas educacionais do mundo até 2030. O secretário de educação Herman Voorwald 
Essa é uma questão, parece-me, muito importante. Ela precisará ser mais bem compreendida em seu alcance e implicações, no que pesquisas posteriores poderão oferecer contribuição. No espaço deste artigo, desejo apenas sublinhar uma faceta desse "mercado de consultorias". Mercado combina com oferta e compra de produtos. Ora, os métodos de management "se tornaram produtos sobre um mercado de condução da mudança e da optimização"(Dujarier, 2010, p. 152). Nessa perspectiva, o que está em jogo é menos a necessidade institucional ou organizacional que o interesse do ofertante, ávido por obter contratos de prestação de serviço e vender seus dispositivos gerenciais. Estes últimos "devem pois ser renovados regularmente" (idem, ibidem), de modo que alimentem seu consumo e sejam alimentados por ele. Os gabinetes de consultoria, sublinha Bernard Dugué (2010), precisam encontrar sua parcela de mercado, assim "vendem frequentemente tudo e não importa o quê, desde receitas antigas apresentadas como novas até métodos manipulatórios próximos de práticas sectárias" (idem, p. 117).

As zonas cinzentas que se formam nesse mercado não poupam ninguém e dão margem a todo tipo de práticas contraditórias. Por exemplo, se a lógica é a da venda de serviços de consultoria e pacotes gerenciais, as firmas de consultoria deslocam-se em um campo bastante vasto: do setor bancário, passando pela área da saúde até a área da educação. Ainda que possam atuar em setores com os quais tenham mais afinidade, elas nada sabem sobre a efetiva realização do métier bancário, soldador naval, médico neurocirurgião etc. - nas situações concretas sobre a qual pretendem intervir. Disso resulta que, circulando em uma lógica de venda de serviços como assinalada no parágrafo anterior, esses dispositivos de gestão são forçosamente construídos na externalidade das situações de trabalho e sem contar com a participação dos assalariados. Dugué (idem, ibidem) resume bem os termos de tudo isso:

É um círculo vicioso: mais os sistemas organizacionais são concebidos e implantados sem ter em conta o trabalho real, mais será necessário instituir ferramentas de controle que terão a dupla função de canalizar a atividade dos assalariados em direção aos objetivos fixados e de verificar se as regras definidas estão bem aplicadas apesar das inevitáveis imprevistos aos quais é preciso fazer face. Operação de direcionamento no início e verificação de que cada um está dentro do determinado em seguida. Velho demônio do taylorismo, o controle da atividade dos assalariados toma hoje a aparência da autonomia, do diálogo [...].

Em tal horizonte, abre-se espaço para todo tipo de contradição: dirigentes e consultores não avaliam formalmente os próprios sistemas de avaliação colocados em prática, eles não têm os meios e nem mesmo o interesse, pois mudam rapidamente de posto, de organização etc., antes mesmo que possam fazê-lo (Dujarier, 2010); de outra parte, o exercício profissional em um contexto de fortes injunções - e no qual

explica: "Para alcançá-la, a consultoria externa nos dará método, disciplina e acompanhará o andamento das ações”. 
a avaliação tem consequências importantes - pode conduzir a modos operatórios cada vez mais desconectados da realidade e dos recursos disponíveis nas situações de trabalho, muito embora alinhados à conformidade esperada: produz-se, nas palavras de Lhuilier (2012, p. 27), um simulacro do trabalho, este "põe em cena uma violação do trabalho que contribui maciçamente para o desconhecimento do real do trabalho e dos processos de degradação da saúde no trabalho”. Mas consultores e dirigentes restam tranquilos: os relatórios estão preenchidos, reuniões foram realizadas, formulários foram entregues, as taxas estão dentro da normalidade, não há greves. Olhando do alto, da cabine do avião, funciona.

\section{CONCLUSÃO}

Neste texto argumentei que a racionalidade gestionária, por diferentes vias, apresenta-se e cobra sua força na área educacional, no que destaquei a delicada situação dos professores e de seu trabalho. Argumentei que as políticas e práticas de gestão contemporâneas, guiando-se com base na díade avaliar-gerir, parecem empiricamente inconsistentes e, não raro, contraproducentes no tocante às suas proposições de desenvolvimento da educação escolar. Com base na relação entre trabalho e gestão, argumentei que esta última encontra-se - mesmo que por muitas mediações, e quer se queira ou não - com o trabalho humano nas situações concretas.

Em tal domínio, as contradições se dilatam à medida que o trabalho é portador de uma complexidade irredutível e ao passo que certos desenvolvimentos recentes da sociedade e das próprias práticas gerenciais estendem mais e mais opacidade sobre ele. Em suma, aquilo que é visível não é o trabalho real, aquilo que se avalia não se conforma à medida e aquilo que se pretende gerir, ao fim das contas, não é o efetivamente gerido. Nesses termos, se considerarmos que não há educação escolar sem o trabalho dos professores, pode-se inferir que a questão aqui posta para os gestores não é pequena e interroga por dentro suas práticas e o ideário que as acompanha. Decididamente essa é uma questão da maior importância, pois diz respeito à própria efetividade - e também ao futuro - da educação escolar.

Se o que foi exposto nos parágrafos precedentes faz sentido, a mudança das políticas e práticas de gestão é imperativa. A rota que estas seguem não parece desejável do ponto de vista dos valores democráticos, como também parecem seguir por uma via que arrisca estreitar-se cada vez mais. No limite, pelos vários motivos aqui expostos, são políticas e práticas deletérias dos que se propõem a gerir. Exatamente por isso é pertinente retomar o sentido político e humano da educação escolar. Pode-se perguntar de maneira direta, à maneira de Ravitch (2011, p. 256), "o que nós queremos obter quando enviamos nossas crianças para a escola?" A resposta, todavia, não vem sem o mal-estar da nitidez daquilo que nos vem sendo oferecido e do direito que nos vem sendo negado. Com as palavras da autora, encerro o presente texto:

Certamente nós queremos que eles [as crianças, os alunos] sejam capazes de ler, escrever e operar com os números. Essas são habilidades básicas que fundamentam todos os outros aprendizados. Mas isso não é suficiente. Nós queremos 
prepará-los para uma vida útil. Nós queremos que eles sejam capazes de pensar por si mesmos quando eles estiverem lá fora no mundo por conta própria. Nós queremos que eles tenham bom caráter e que tomem decisões sãs sobre sua vida, seu trabalho e sua saúde. Nós queremos que eles enfrentem os prazeres e dificuldades da vida com coragem e humor. Nós queremos que eles sejam amáveis e compassivos em suas relações com os outros. Nós queremos que eles tenham um senso de justiça e igualdade. Nós queremos que eles compreendam o nosso país e o nosso mundo e os desafios que nós enfrentamos. Nós queremos que eles sejam cidadãos ativos e responsáveis, preparados para pensar questões cuidadosamente e até o fim, a escutar diferentes visões e a chegar a conclusões racionalmente. Nós queremos que eles aprendam ciências e matemática e participem da busca por soluções. Nós queremos que eles desfrutem da rica herança artística e cultural de nossa e de outras sociedades. (idem, ibidem)

\section{REFERÊNCIAS}

Afonso, A.J. Nem tudo o que conta em educação é mensurável ou comparável: crítica à accountability baseada em testes estandardizados e rankings escolares. Revista Lusófona de Educação, Lisboa: CeiED, n. 13, p. 13-29, 2009.

Alves, W.F. O trabalho dos professores: saberes, valores, atividade. Campinas: Papirus, 2010.

. Delírios da gestão: crítica à razão gestionária na educação - o ponto de vista do trabalho. In: Congresso Ibero-Americano de Política e Administração da Educação, 3., 2012, Zaragoza, Espanha. Anais... Zaragoza, 2012.

Ball, S. J. Profissionalismo, gerencialismo e performatividade. Cadernos de Pesquisa, São Paulo: Fundação Carlos Chagas; Campinas: Autores Associados, v. 35, n. 126, p. 539-564, dez. 2005.

Baunay, Y.; Cahovet, M.; Grosse, G.; Oliver, M.; Rallet, D. (Coord.). Le travail enseignant: le visible et l'invisible. Paris: Syllepse, 2010.

Bidet A.; Vatin, F. Mesure et acteur au travail. In: Steiner, P.; Vatin, F.(Dirs.). Traité de sociologie économique. Paris: PUF, 2009 (Quadrige).

Bruno, I. La recherche scientifique au crible du benchmarking. Petit histoire d'une technologie de gouvernement. Revue d'Histoire Moderne et Contemporaine, Paris: Belin, n. 55-54 bis, p. 28-45, 2008.

Clot, Y. Le collective dans l'individu? In: Congrès de la SELF: Modeles et pratiques de l'analyse du travail, 38., 2003, Paris. Actes... Paris, 2003. Disponível em: <www. ergonomie-self.org>. Acesso em: nov. 2008.

Le travail à coeur. Paris: La Découvert, 2010.

Codo, W. Prototeoria: síndrome do trabalho vazio. In: (Org.). O trabalho enlouquece? Um encontro entre a clínica e o trabalho. Petrópolis: Vozes, 2004.

Coutarel. F.; Daniellou, F.; Dugué, B. La prévention des troubles musculo-squelettiques: quelques enjeux épistémologiques. Revue @ctivités, Paris: [s. n.], v. 2, n. 1, p. 3-18, avril 2005. 
Dale, R. Globalização e educação: demonstrando a existência de uma "Cultura Educacional Mundial Comum” ou localizando uma "Agenda Globalmente Estruturada para a Educação"? Educação E Sociedade, Campinas: CEDES, v. 25, n. 87, p. 423-461, maio/ago. 2004.

Donadone, J.; Sznelwar, L. Dinâmica organizacional, crescimento das consultorias e mudanças nos conteúdos gerenciais nos anos 90. Produção, São Paulo: EPEUSP, v. 14, n. 2, p. 58-69, 2004.

Dugué, B. La folie du changement. In: Thèry, L. (Dir.). Le travail intenable: resistir collectivement à l'intensification du travail. Paris: La Découvert, 2010.

Dujarier, M.-A. L'automatisation du jugement sur le travail. Mesurer n'est pas évaluer. Cahiers Internationaux de Sociologie, Paris: PUF, v. CXXVIII-CXXIX, p. 135-160, 2010.

Fernandes, M.J. S. As recentes reformas educacionais paulistas na visão dos professores. Educação em Revista, Belo Horizonte: UFMG, v. 26, n. 3, p. 75-102, dez. 2010.

Freitas, L. C. Os reformadores empresariais da educação: da desmoralização do magistério à destruição do sistema público de educação. Educação E Sociedade, Campinas: CEDES, v. 33, n. 119, p. 379-404, abr./jun. 2012.

Friedmann, G. Problèmes humains du machinisme industriel. Paris: Gallimard, 1946.

GAdrey, J. Emprego, produtividade e avaliação do desempenho dos serviços. In: SAlerno, M. (Org.). Relação de serviç̧o: produção e avaliação. São Paulo: SENAC, 2001, p. 23-65.

Guérin, F. Laville, A.; Daniellou, F.; Duraffourg, J.; Kerguelen, A. Compreender o trabalho para transformá-lo: a prática da ergonomia. São Paulo: Edgard Blücher, 2001.

Guisbond, L.; Neill, M.; Schaeffer, B. A década de progresso educativo perdida sob a NCLB: que lições tirar desse fracasso político? Educação E Sociedade, Campinas: CEDES, v. 33, n. 119, p. 405-430, jun. 2012.

Hubault, F. Do que a ergonomia pode fazer a análise? In: Daniellou, F. (Coord.). A ergonomia em busca de seus princípios: debates epistemológicos. São Paulo: Edgard Blücher, 2004. p. 105-140.

Jeffrey, B.; Woods, P. Testing teachers: the effect of school inspections on primary teachers. London: Falmer Press: 1998.

Lessard, C. L'obligation de résultats en éducation: de quoi s'agit-il? In: Lessard, C.; Meirieu, P. (Eds). L'obligation de résultats en éducation. Bruxelles: De Boeck, 2008. p. 23-48.

Lhuilier, D. A invisibilidade do trabalho real e a opacidade das relações saúde-trabalho. Trabalho E Educação, Belo Horizonte: UFMG, v. 21, n. 1, p. 13-38, jan./abr. 2012.

Linhart, D. A desmedida do capital. São Paulo: Boitempo, 2007.

Melo, H.; Marques, O. R. B. Serviços e trabalho precário: um olhar sobre o Rio de Janeiro. In: Departamento Intersindical de Estatística e Estudos Socioeconômicos; Centro de Estudos Sindicais e de Economia do Trabalho (Orgs.). O trabalho no setor terciário, emprego e desenvolvimento tecnológico. São Paulo: DIEESE; CESIT, 2005. p. 177-192.

Merrien, F.-X. La nouvelle gestion publique: um concept mythique. Lien Social et Politiques, Paris: Érudit, n. 41, p. 95-103, 1999. 
Meuret, D. Gouverner l'école: une comparaison France/États-Unis. Paris: PUF, 2007. Mons, N. Effets théoriques et réels des politiques d'évaluation standardisée. Revue Française de Pédagogie, Lyon: ENS Éditions, n. 169, p. 99-140, oct./déc. 2009.

Normand, R. De l'accountability aux standards: la traduction européenne des politiques de la performance. In: Colloque “Lévaluation des politiques D’ Éducation eT FORMATION”. UMR, Lyon, 12 et 13 sept. 2005.

Orban, E. O serviço é um produto? In: Departamento Intersindical de Estatística e Estudos Socioeconômicos; Centro de Estudos Sindicais e de Economia do Trabalho (Orgs.). O trabalho no setor terciário, emprego e desenvolvimento tecnológico. São Paulo: DIEESE; CESIT, 2005. p. 11-20.

RAvitch, D. Vida e morte do grande sistema escolar americano: como os testes padronizados e o modelo de mercado ameaçam a educação. Porto Alegre: Sulina, 2011.

Schwartz, Y.; Durrive, L. (Orgs.). Trabalho e ergologia: conversas sobre a atividade humana. Rio de Janeiro: Editora da Universidade Federal do Rio de Janeiro, 2007.

Sousa, S. M. Z. L. Avaliação do rendimento escolar como instrumento de gestão educacional. In: Oliveira, D. A. (Org.). Gestão democrática da educação: desafios contemporâneos. Petrópolis: Vozes, 2005. p. 264-284.

Stroobants, M. Sociologie du travail. 2. ed. Paris: Armand Colin, 2007.

Supiot, A. Homo juridicus: ensaio sobre a função antropológica do direito. São Paulo: Martins Fontes, 2007.

Vatin, F. Le travail et ses valeurs. Paris: Albin Michel, 2008.

Vidal, M.; Muniz, H.; Alvarez, D. Terá a atividade um lugar na avaliação de performance do setor de serviços? Revista Ação Ergonômica, Rio de Janeiro: Abergo, v. 1, n. 2, p. 79-91, 2001.

\section{SOBRE O AUTOR}

Wanderson Ferreira Alves é doutor em educação pela Universidade de São Paulo (USP). Professor da Universidade Federal de Goiás (UFG). E-mail:wandersonfalves@yahoo.com.br 